\title{
Keeping the Internet Open
}

The Internet has always been open, or so it has been for much of its existence. Open to new ideas, new protocols, new applications, and new technology. But not everyone or

every regime sees the bounty of freedom of expression and invention. Some see an open wound into which every source of pestilence pours. Threatened by sunlight, authoritarian governments seek to shutter freedom of access to this creative infrastructure. They point to the worst content, the harmful malware and the cyber-attacks that damage the users of the Internet to justify their policies and rhetoric. And, in this, they are not entirely wrong. There is malware and there are serious cyber-attacks and weaknesses. Some regimes, while speaking out against these challenges, even contribute to them by sanctioning or launching their own attacks.

Those who maintain, operate, and evolve the Internet have an obligation to find ways to protect its users from these very threats. Those who offer and who benefit from the cornucopia of applications the Internet can support have an opportunity to contribute to the safety, security, privacy, and reliability of the Internet upon which so many now depend and so many more wish to have access.

To those who have spoken for and who espouse an open and welcoming Internet now falls the task of keeping it that way. To do so will require more than words and argument. Substantive improvements in the Internet's resilience and resistance to attack are needed. Firewalls and passwords are not enough. Strong authentication, cryptography, and attack-resistant operating systems, browsers, and other applications are needed. Better programming environments that produce less buggy, exploitable software are necessary and await invention or use.

Nor can the users of the Internet escape some responsibility. Their poor choices of passwords and naïve clicking on phishing email messages, with their virus-laden content, open pathways for those with harmful intent. We have an obligation to teach safe network usage and practices to all who look for positive utility in this global network of networks. In a society of laws, the freedom we enjoy comes in part from protection against the harmful actions of law-breakers. We rely, in part, on enforcement of the law to maintain the safety that we, and our fellow Internauts, wish to enjoy. But in some societies, laws that limit freedom of expression, peaceful assembly, and access to information stifle the benefits that derive from freedom, and mock the very openness that lies at the heart of the Internet. Irrational responses to real and perceived potential harms lead to unenforceable legal regimes and do more damage than good.

Readers of this column should feel some measure of responsibility to fashion new and apply known means to increase the safety and security of the Internet while fostering the evolution of new and increasingly useful applications. In some very direct sense, computer science and engineering house the knowledge and methods needed to achieve these goals. Designs and practices that resist cyber-attacks of all kinds are needed. But this challenge will not be successfully met solely with technology. Transnational standards of behavior will be needed for individuals, corporations, and even nations, if we are to keep the Internet open and to avoid catastrophic closing of its boundless shores.

As the Internet infrastructure becomes increasingly vital to the global economy and well-being of Internauts everywhere, nations will need new practices to respond to perceived national security threats. Cyber-hotlines, like those created in the tense days of the Cold War, may prove essential to avoid offensive cyber or even military responses to cyber-attacks subject to misattribution of origin. Misunderstandings between nations or even between domestic citizens and law enforcement can visit untold harm on everyone and lasting damage to freedom in its many dimensions. Just as DNA analysis has proven to be a powerful, if not always perfect, tool for truth, a cyber-counterpart may be needed to aid in the identification of criminal actors pursuing their aims along domestic or transnational courses.

What we should not and must not tolerate is the arbitrary shutting down of pathways that can and do link together our increasingly global societies. Discovery of diverse cultural, literary, and historical heritage, and their digital preservation should animate our purpose in keeping the Internet open. Online facilitation of commerce of all kinds has enhanced our lives. Every person on the planet should have the freedom to access and to contribute to the increasing utility of the Internet. Four decades have passed since its invention and we still have work ahead to assure its utility for many decades to come until it, too, is replaced by something even better and more beneficial.

Vinton G. Cerf is vice president and Chief Internet Evangelist at Google. He served as ACM president from 2012-2014.

Copyright held by author. 